\title{
Playing the Intercorporeal: Frankenstein's Legacy for Games
}

With so many games falling into the generic categories of science fiction and horror, and very frequently calling on vocabularies of the Gothic, you'd expect at least one or two direct adaptations of Shelley's Frankenstein. While there are legions of vampire and zombies, the legacy of Frankenstein for games is far more subtly manifest than with all those other monsters. This paper analyses some of the ways in which games carry the Frankenstein legacy, from the 'stitched horrors' of World of Warcraft to the monsters of Half-Life. Focusing on monsters and mad scientists, the paper creates a map for understanding the terrain of legacy for games. I start with a general examination of the terrain including signalling how the posthuman in games is often highly indebted to Shelley's novel. I then move to address moral and existential dimensions of this legacy evident in many games that draw on Gothic approaches to science (Half-Life and Bioshock for example), focusing on the ambiguity of monster/creator and the operation of hubris. I tie these elements into the paper's main focus on death. Here I am concerned with the pleasures of games for players as well as with representational forms. My core claim in the paper is that games and Shelley's Frankenstein (the character and the novel) are predicated on a denial real of death. This is a gambit I shall explain and explore. As the paper draws to a close my argument becomes clear: the reason that the legacy is (pervasively) implicit rather than explicit in games, is due to the fact that the denial of death in games is structural (and crucially not thematic as it is in Shelley's novel). This is why the novel is tragic, while the death-defying normative vocabularies of games entail that tragedy is near impossible games therefore offer a very different form of catharsis.

\section{Context}

Move to show that the legacy of $\mathrm{F}$ is subtle yet very present in games (as indeed is it present in the ways we tended to narrativize technologies that are closest to mimicking human consciousness).

Horror and Science Fiction (SF) are genres very regularly called by game developers to add easily marketable flavour to games. Some of the earliest digital games drew on Science Fiction-based themes and iconography, including what is often regarded as the first videogame ever made, Spacewar! (1962). Games and SF are mutually supportive, as computing is itself a form of Science Fiction, often sold and given imaginative traction as such and providing one of the genre's stock characters. An abundance of synthetic intelligences is dreamed up by SF developers and computational creativity researchersi. The dominance of dystopian narratives, demonic synthetic and alien entities in SF does however make for an obvious blend with Horror. This resolves around the dramatic use of that which threatens normative definitions of the human and humanity, providing game developers with a scenario that integrates easily into different game genres, such as the First-Person Shooter, Action-Adventure, Puzzle, Tactical and Strategy games. Games gain thereby iconographies of spectacle, narratives that rest on conflict and exploration and well established audiences. While SF regularly takes a wide-angle, epically-scoped view, Horror tends to focus on the constrained and the claustrophobic. Often in SF-Horror hybrids the one is nested in the other, as is evident in films as diverse as Solaris (1976, USSR), Forbidden Planet (1956, US), Moon (2009, UK) and the Alien franchise. But the strongest bonding agent between the two is monstrosity. Monsters have global appeal and which evident in a vast range of culturally diverse mythologies but it is Mary 
Shelley's Frankenstein: or, the Modern Prometheus (henceforth Frankenstein) that provides the monstrous blueprint for blends that I'Il name 'Gothic Science Fiction'ii. Given the regularity with which game developers have called on Horror and SF, and their hybrids, it is then surprising how few direct game adaptations of Mary Shelley's Frankenstein there are. This is particularly notable given the number of films, plays and TV serial adaptations there have been: the play version of the novel staged in 1823 and film adaptations of 1910 and 1915, as well as the many subsequent films and plays speak of the transmedial potential of the text. What direct adaptation games there are however represents just a handful of unambitious and small scale offerings, the most substantial of which appeared during the 1990s, perhaps on the back of much-publicised Kenneth Branagh's film version of the novel (1994). In addition, while there is plenty of critical commentary on science fiction and monsters in games, to date there has been no work that focuses specifically on games and Frankenstein. To establish the terrain occupied by games in the Frankensteinian landscape, this essay begins by positioning the main ludic and thematic coordinates of these direct 'gamified' adaptations. Its main task is however to explore what I regard as the more significant and interesting arena of the novel's indirect legacies within digital games and their computing systems, focusing on themes of Monstrosity, Creativity, Death and Synthetic Intelligence.

\section{Direct Adaptations}

Direct game adaptations of Frankenstein do not line up to a single game genre. Instead the few that have been made are split across multiple genres, suggesting therefore that the novel can be 'gamified' in very different ways. A text-based adventure game was designed by Rod Pike and Jared Derrett and published in 1987 for Amstrad, Commodore and ZXSpectrum consoles. The game offered players a close rendition of the novel in text form; players typed in 'actions' (verbs) to progress the story. As text, little computing power was needed and the game makes meaning through its combination of verbs, descriptive text and evocative language ('darkening clouds', 'wild white horses of foam'), that latter set to spark a player's imaginative engagement and to reference very directly Shelley's own written style (there are also 'pixel art' number of images to set scenes that in their blocky nature bear some resemblance to woodcuts). The visual nature of the text is typical of the capacity of the consoles of the time: hard to read because of the large kerning space between letters, yet in its lack of letter size uniformity has an eccentric charm and resonates with simple typesets. In terms of its core 'game loop' (a term used by game designers to describe the specific nature of a game's interaction), there is a very simple form of call and response, leaving intact the rich literary source for the game. 


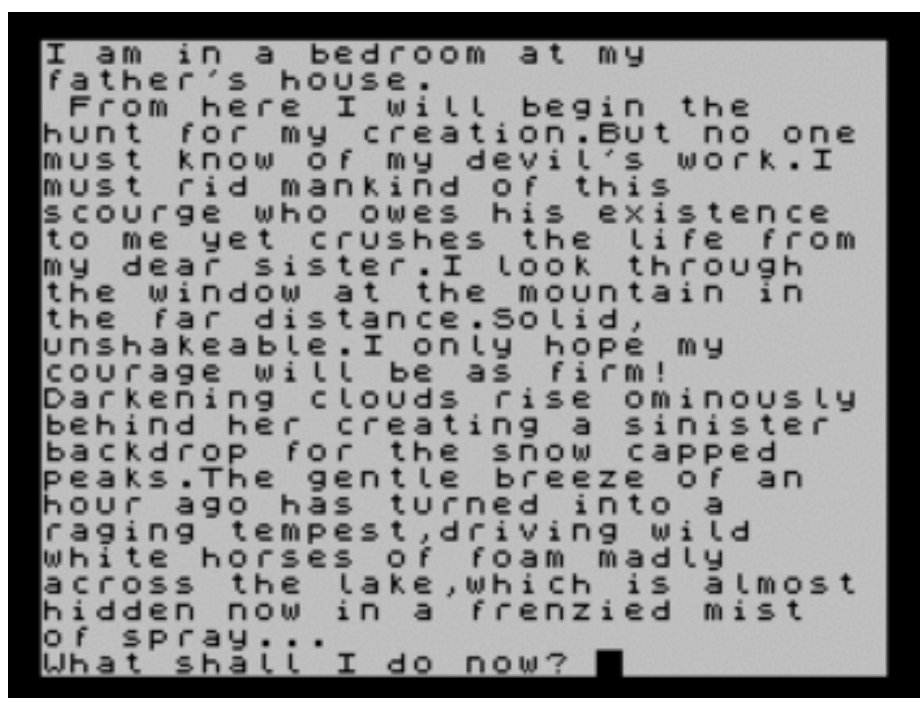

Fig 1 Screenshot Frankenstein (1987, CRL Group). The game can be sourced https://archive.org/details/zx Frankenstein 1987 CRL Group Part 1 of 3

In addition to its strong relationship to the novel, the game makes use of the novel's dynamic shifting viewpoint. In its first two parts the point of view is that of Viktor, while in the last part, its switches that of the Monster. This switching is something rather unlikely in most contemporary first or third person games, or in role-playing games, where a switch would be regarded as destabilising a player's conditions of presence in a game. Unlike most 'action-based games that rely on heroes as the point of identification for the player, this first Frankenstein game sought to preserve the tone and textuality of the novel thereby using a game loop designed to bring the player into the game as a literary text.

This 'literary' approach to gamifying the novel is also present in a later game, Frankenstein: Through the Eyes of the Monster published in 1995 for a range of platforms, although its reference to the literary is much diminished. Here cinematic vocabularies and iconography are called upon, alongside the introduction of new characters and an altered storyline. Alongside the use of short video clips that lend a cinematic quality to the game, is the use of written sources to help tell its story of Philip who Viktor Frankenstein has brought back from the dead after he's hung in error for the murder of his daughter. Philip/the player wakes at the start of the game without memory. This device provides the rationale for the player to remain located in the present tense, yet motivated to unearth who he is and then to seek out his daughter's murderer. The game builds story strongly into its game loop through its exploratory and hermeneutic mode. It therefore sits between the text-based adventure and action-based games that often tell their stories not through written text but instead through, borrowing from cinema, semiotic-rich environments traversed by the player-character and dialogue. As such the game does not switch point of view, and unlike the ways in which film divorces point of view from character, it is anchored to the one character. This is a temporal and spatial property common in the ways games tell stories that differs from other media. It is designed to position the player very directly into the frame of action (emphasising the active role of play).

The intention to reach more diverse markets than was previously the case has defined the 'ecosystem' of games over the past few years. Aided by digital downloads and the mobile market, this has seen the rise of what are often termed 'casual games', games that offer experiences that are less frenetic and require less game literacy than those high production value games made for the 
console and PC markets. Despite the lack of games that adapt Frankenstein in this contemporary market place, there are (oddly in my view) two PC-based casual games that refer directly back to the novel, one is more literary than the other. These are: Frankenstein: The Dismembered Bride (henceforth Dismembered Bride) published by Good Game (via Rocky Horror) [free to download from publisher Good Game gametop.com developed by HdO Adventure] and Frankenstein: Master of Death (Jetdogs/Fineway, 2015) (hence forth Master of Death). Both are low-budget, point-andclick style puzzle games. The first takes a tongue-in-cheek, shlock comedic approach, name checking The Rocky Horror Picture Show (1975) through its protagonists Brad and Janet. Brad sets out to rescue the pieces of Janet's body that can be found secreted around the Castle, guided by her disembodied brain. This 'find the body parts' approach to gamifying Frankenstein is also found in earlier games such as Dr. Franken (1992), published for the SNES. I have myself designed a game (it never got beyond a design idea) that involved stitching body parts together as a kind of craft activity with the tag-line make your own friends. In its crass literality, the comedic approach draws on a tradition of sending up the Gothic, galvanised by Jane Austen's Northanger Abbey (1817), in so doing deflating the necessary pretention required to construct a Gothic frame for rendering metaphysical matters related to the (post) human. Such reframing of the genre is perhaps more suitable in the context of games for a casual and therefore populist market looking for low-commitment distraction.

Frankenstein: Master of Death uses the same point-and-click puzzle format, but it takes the subject matter much more seriously and as such can be thought of within the frame of Gothic Science Fiction. Its puzzles are therefore more intricate and well-crafted than those of Dismembered Bride. There are many such games based on Gothic literary subjects, some featuring writers like Edgar Alan Poe and Nathaniel Hawthorne. Perhaps taking their cue from Poe's blueprint detective Dupin, these games place the player as detective. The puzzles in this case are quite diverse, there are maze puzzles, jigsaw-style puzzles along with the staple hunt the object static screens present in most of the locations in which the game take place. The solution of these puzzles provide access to objects need to unlock new areas. 2D games are do not provide players with the unified spaces that can be run around in of most videogames, instead each room or area of the game space is presented from 3 or 7 angles, each area to be explored in depth. This slows down the pace and is more akin to reading in terms of attention to the information presented on screen. The game does have points of excitement, provided by simple cut scenes. In this case these represent the nodes of the story beginning with the Monster abducting Viktor's wife, Elizabeth. In this version however, Viktor needs to be rescued and was the innocent victim of his patron Baron Igor. Successful traversal of the puzzles finds Viktor and Elizabeth rescued, the Monsters freed from his miserable existence and the evil Baron apprehended all due to the perspicacity of the player. As the game publicity says: "Help restore the course of nature and save Victor and his wife, Elizabeth!" This resolution overturns the moral ambiguity of the novel, in favour of the claim that games makes on having a winning condition to fulfil as a means of pleasing the player. While the game is well-crafted it still seems to follow the well-worn path of games to eschew the tragic mode that gives full character to Gothic Science Fiction.

A very different approach in a ludic sense is taken by Frankenstein: The Monster Returns, made for the NES in 1990. This game was made in that flush of Frankenstein games made in the early 90s, but this one is indicative of a shift much further away from more direct adaptations. Here any literary based elements are side-lined in favour of a more verb-based game grammar. The vocabulary of the game loop is far more action-based therefore, favouring a side-scrolling platform adventure format punctuated with beat-'em-up style elements. The game's 'return' is less to Shelley's novel and more to the arcade and to iconography of Universal's cinematic Frankenstein, all bolts, blanket stitch and 
flattened head. In the context of the arcade game the monster's monstrosity becomes a cypher, simply providing a familiarity rather than something potently uncanny as was the intention of Shelley's monster and indeed Theodor von Holst's illustration of the monster published in 1831. Ironically it is this illustration, with its Blake-like anatomy, black greasy locks and haunted look, that is called on more recently by adaptations such as in the TV series Penny Dreadful wherein the tragedy of the monster's situation is more intently present. For future reference then we might refer to a core difference between representations of the monster in terms of a supernatural entity or a more scientific one. Certainly, in both cases the of zombies pop culture are linked genetically to Frankenstein's legacy (both in terms of the novel and Viktor's machinations).

\section{Indirect}

Having looked at the bulk of the existing direct adaptation games and ascertained some of the ways in which gamification has tended to diminish the tragic core of the novel that sets the definition of Gothic Science Fiction, I turn now to more diffuse examples of Frankenstein's (and von Frankenstein's) legacy. As you might expect this takes us into the generic realm of monsters and mad scientists and leads us into an analysis of the monstrous, dystopian and death in games. In addition, uses of synthetic intelligence (Al and procedural generation) in the computing that underlines some videogames is also regarded in terms of the novel's bequest.

Developed and published by US game studio Blizzard, World of Warcraft (2005-present) (WoW from hereon) is a massively multiplayer role-playing online game that has had its peak over 11 million subscribers worldwide. While this game is in any way a direct adaptation of the novel, it's themes and related iconography provide the game with one of its key formal strands. The Warcraft franchise is mainly indebted to Tolkien's world creation, a franchise that carries an echo of Frankenstein in the origination and figuration of the Uruk' hai. Blizzard has however evolved its game-led approach to its world design since the release of its first game Warcraft: Orcs \& Humans in 1994. WoW splits its players into two contesting factions, Horde and Alliance. Each faction includes a variety of races drawn from the fantasy canon (Elves, Orcs, Undead, Humans, Dwarves etc). Unlike Tolkien's moral Manicheanism, WoW subscribes to far more relativist moral structure. Crimes and cruelty have been perpetrated on both sides; alliances are common but often break providing the source of tension and keeping conflict in play over the franchise's evolution. Core to this is the use of corruption as a dramatic and thematic device and it is this that hooks the game so strongly into Frankenstein's legacy, translating into it into the characteristic lore, ludic and visual grammar of the Warcraft world. Central protagonist characters such as Arthas, Gul'dan, Illidan Stormrage, and Grom Hellscream, as well as lesser characters such the Barov family, within the game and its paratexts are seduced by the immense power and immortality offered by demonic forces, which constantly threaten slavery, dehumanisation and annihilation. As such corruption of such characters leads to betrayal, genocide and, in the case of Arthas, patricide. This formula gives the game it's enemies and their machinations involves the use of demon science as a means of reanimating the dead, thereby transgressing the most basic means of defining social and individual existence. Such threat was established in Warcraft 3, wherein the necromancer demon Kel'Thuzad turned humans to a mindless, violent zombie army. In the Warcraft world, there is no differentiation between science and magic, each are co-opted into struggles for, and exercise of, power and control. It can be wielded by players and has a ludic function as well as providing a pillar of the game's mythos.

We can also distinguish the Frankenstein legacy at work within both player classes and races in the game. The classes Warlocks and Shadow Priests for example can wield demonic powers, both able to surrender life (gamified as health points) for power, and Shadow Priests' power is based on gradually trading sanity for power much as Frankenstein traded his life and sanity for knowledge and power. It 
is however the Undead race this has closest links to the theme of reanimation. The Undead were originally simply enslaved to the Lich King, known therein as The Scourge, but some regained their free will when his defences were down, forming a rebel group known as the 'Forsaken', lead by Lady Sylvannus Windrunner. If a player chooses to play as an Undead character, they find themselves at the start of the game resurrected by a Val'kyr and informed of Forsaken heritage, included a hatred of humans who betrayed them under the leadership of Arthas Menethil. The choice of character models available include for female Undead Universal's iconic 'Bride' hair style (see Fig 2). The Forsaken race also draw on other aspects of Universal Horror, with the male characters often voiced in upper-class British accents and they are mainly shown as Alchemists or Apothecaries, seeking thereby to create poisons that will kill humans and resurrect the dead but who remain with free will. As such the Undead locations of the game are also dressed in guises that draw heavily from Universal's representation of Frankenstein's lab and electrical equipment (Fig. 2, 3, 4), with a heavy emphasis on an acid green light that glows to produce an eerie and unnatural atmosphere, colour also associated with the decayed flesh of colour renditions of Frankenstein' monster.

In terms of mythos (or lore), Frankenstein's legacy is exemplified in the design of Scholomance, a dungeon closely linked to the Scourge ('dungeon' or instance is where a new copy or instance of a location is assigned for a small group or individual). Scholomance is a school used for teaching necromancy, founded by Kel'Thuzad Various storylines and world conditions are informed by Frankenstein's legacy. The Necromancers of Scholomance for example, seek power through darks arts that include reanimation of the dead. for The Undead playable race quests are closely based on a combination of quests Saruman's schemes to build an army or Uruk'hai in The Lord of Rings, finds its articulation in WoW by way of Frankenstein and the Golem. The 'Stitched Horrors' 'Abominations' of WoW are not born of earth however, but made of body parts, admittedly rather cartoonish in keeping with Blizzard's visual vocabulary. In blending necromancers with mad scientists, we have here another version of Gothic Science Fiction. Compacted and overdetermined we have reanimators, necromancers demons, zombies and golems co-opted as cannon fodder and demonstrative of the games conception of 'evil' - against the 'humane' values of the playable factions. So while the game has a far more complex moral structure than the Manichean patterns of many games, there is nonetheless recourse to amoral absolute. This is underlined by the constant use of terms 'unnatural' 'filth' cursed and putrid, this database of dirt seems come straight out of the pages of Mary Douglas and Julia Kristeva's work on boundaries. Undead class, it is the undoing of the hard-line category of death that is where the buck stops. As Muriel Spark has noted of Frankenstein, emphasis is placed on the terms of Horror, 'filth', 'pollution', inversions of the natural order (1987, 159). 

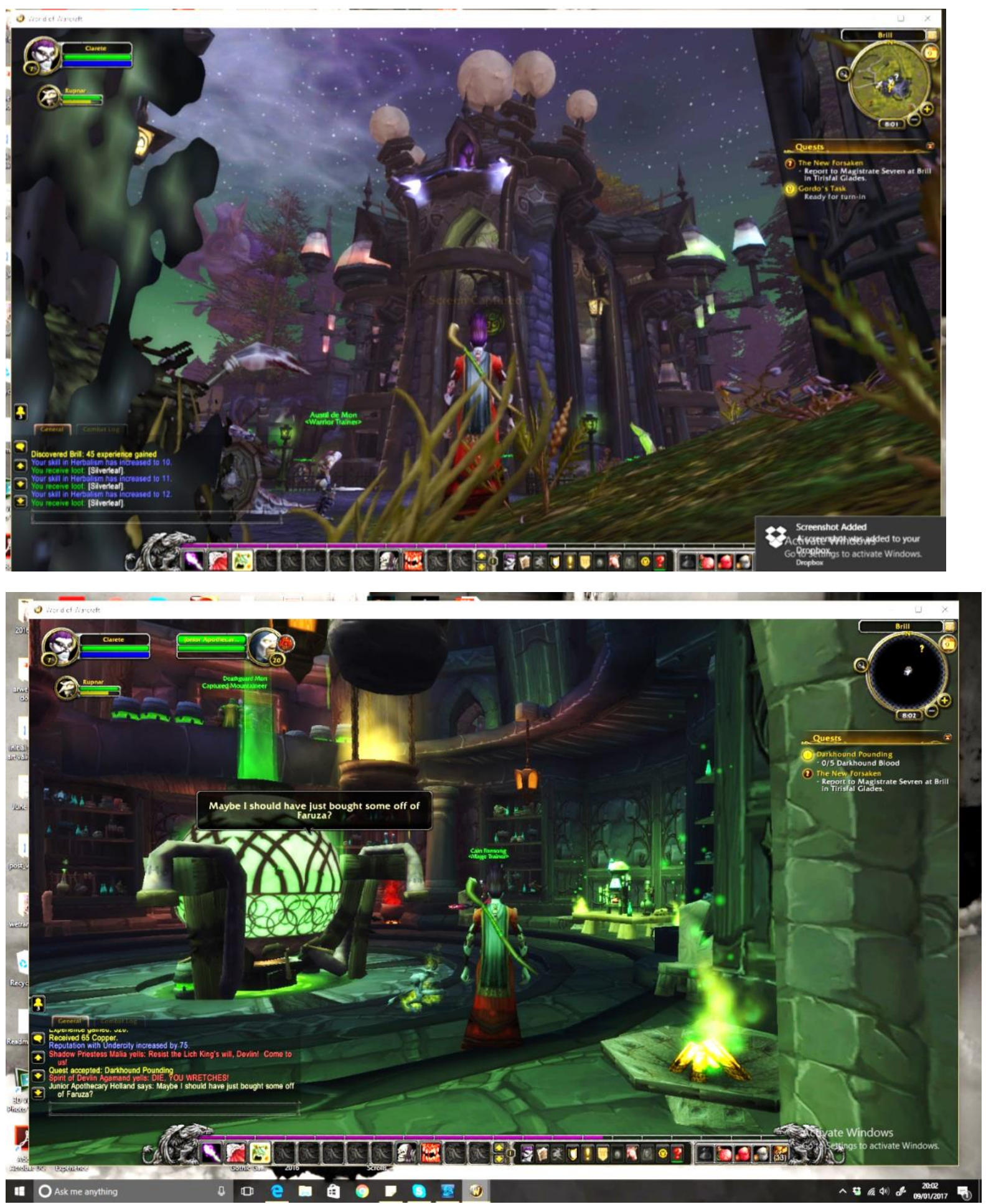


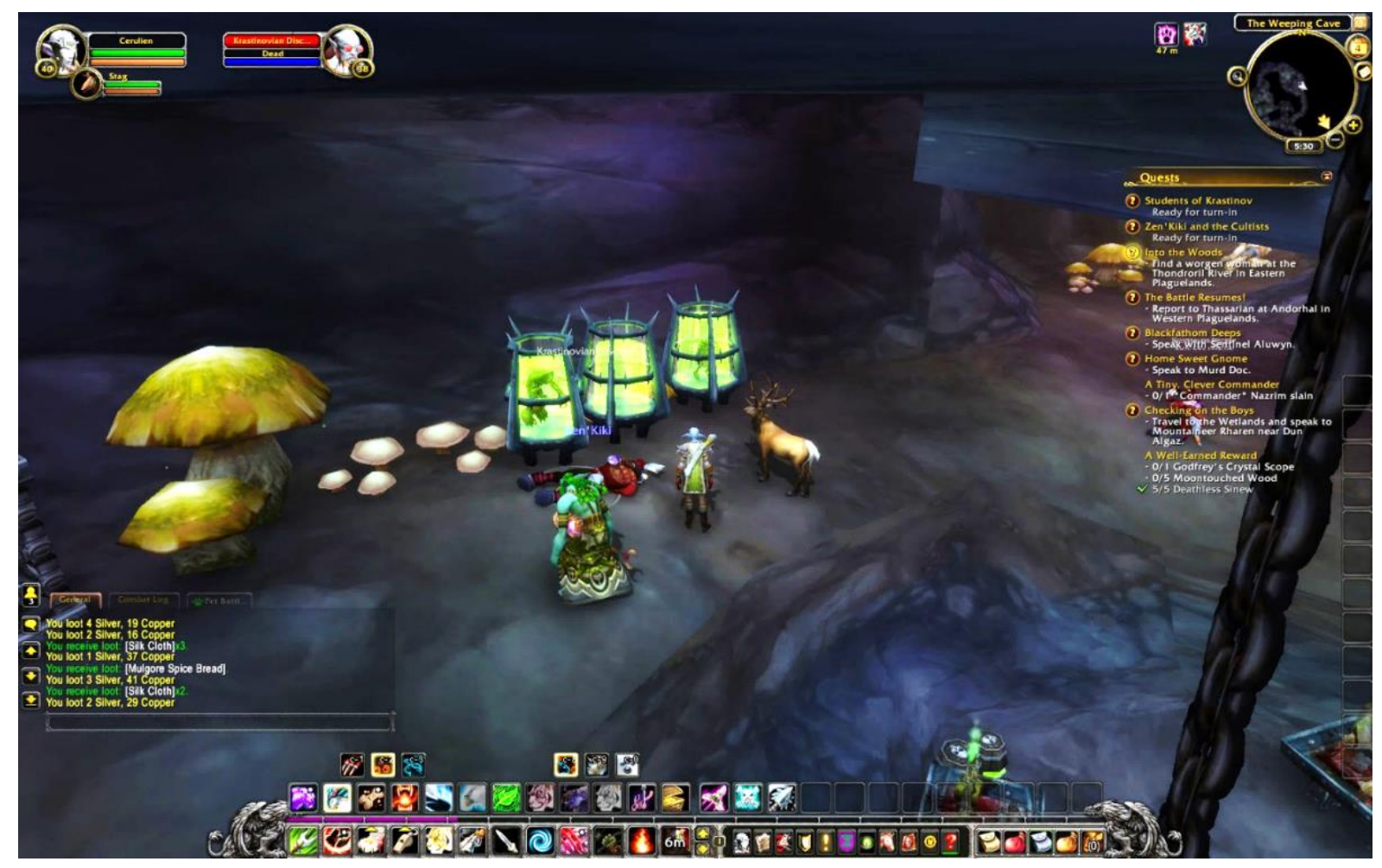

Creating Monsters: Mastery, Death \& Al

Corporeal recombination and reinvention, "filthy creation" as Shelley has Frankenstein put it, is core to Frankenstein and to its artistic, cultural and technological legacy. Such manipulation is often rhetorical or generically framed as diabolical, dystopian or post human, yet it can also be regarded as creative and perverse. Janine Chasseguet-Smirgel (1985) locates creativity within a psychological and perverse process of challenging and over-turning the rule/s of the Father. In this context, creativity is a form of dissent, a refusal of the received "order of things", inclined to make mock, invert convention and radically reinvent. While games certainly do reinvent, they do so through a conventionalised imposition of rules to create goal-directed play. In this sense, they are far from anarchic reinvention machines, laid down by the underlying programming (no matter how complex), their laws are incontrovertible from the point-of-view of the player. Law is not here in itself ideological or cultural (even though the nature of a game's laws can be said to be so), but is instead procedural and constitutive, much as we might say is true of language, where structure exists outside culture, but its expression does not. It is difficult, without specialist knowledge, therefore to

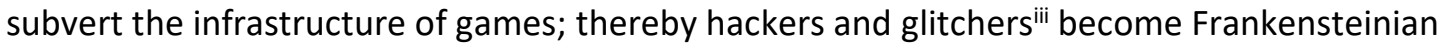
exceptions who can edit or circumvent a game's genetic code. Players then are subject to the "law" of the game, even though games sell themselves on providing players with a sense of agency and mastery of the game system. Game designers however may under some conditions seek to create their game in accord with their own perverse worlds. Certain games such as the first Bioshock, The Stanley Parable and September 12, play artfully, perversely with this scenario but they do so in these cases to highlight a paradox at the heart of videogames that most players overlook. If players play along with the predefined rules and go through all the set hoops, they accrue its pleasures including the achievement a sense of mastery. This mastery is of course highly bounded and localised, often quite hard-won and demanding focus and time, but this is in danger of becoming a compulsion to repeat, that which Freud terms the death drive - which is a form of the denial of real death: I remind 
myself of this every time I make yet another new character in World of Warcraft. As such, videogames might be said to be Frankenstenian in their capacity to invent a new world (albeit virtual), (appear) to cheat death, in their capacity to reset and edit time (I've died...time to try again!) and in the type of mastery they to offer designers or appear to offer players.

Central to Chasseguet-Smirgel's model of perverse creativity is that established modes of defining difference, such as gender, physics or the image of Vitruvian made in the mode of God's sacred geometry, are "unbelieved". Frankenstein's crime is generative; he is a creative and curious practitioner in an age where life was regarded as God's incontestable creation. As Shelley puts it in an account of her own creation "I saw the hideous phantasm of a man stretched out, and then, on the working of some powerful machine, show signs of life, and stir with an uneasy, half vital motion. Frightful it must be; for supremely frightful must be the effect of any human endeavour to mock the stupendous mechanism of the Creator of the world" $(1985,9)$. Seeking to gain mastery over "...the nature of the principle of life" $(1985,8)$, Frankenstein's becomes the Prometheus of his time and as dicated by Hubris, he follows in the footsteps of many audacious creators and makers in mythology (e.g. Arachne, Daedalus, Salmoneus, Niobe). Computing too has the hubristic capacity to allow game makers to reinvent physics and bodies within a game world. Because everything in a videogame is code, even if they do represent and simulate the real world, they are totally manufactured artefacts. The potential for perverse creativity is therefore limitless. For example, at the time of writing, the Norwegian game developer Funcom are advertising a new MMO, Conan Exiles, based on Robert $\mathrm{E}$ Howard's adventurer. As with most role-playing games, players get to choose from a range of developer defined characteristics the look and build of the character they will play in the game. This ability to collage together a character can certainly be regarded in terms of the Frankensteinian legacy, however in the main the creative affordance is limited for players, meaning that a suitably inclined player cannot create hybrids of different character classes. There is no room for a Surrealist exquisite corps/corpse in most videogame-based RPGs. While eschewing liberal corporeal collaging likely to present issues for animation rigging, Funcom do however allow players to customize their character's genitals. This certainly provides a selling point as a way emphasising the Phallic flavour of Howard's creation. Much greater capacity for corporeal collage is however available to interested players in the virtual world Second Life (Linden Labs). This creative capacity lead to a stiff and lucrative trade in player-made body parts. Default characters had no genitals, and taking advantage of the customisability central to this virtual world and its multi-formed citizens, enterprising players sold genitals of many different descriptions to other players, often in support of sexual role-play. In a kind of modern-day Frankensteinian 120 Days of Sodom, genitals became detached from gender and even human form, able to be placed anywhere and made to order. This later example is perhaps the strongest entry into a Frankensteinian perverse creativity in virtual worlds, enabled by the hypothetical and ultimately malleable potential of game technologies. Second Life's ingenuities are edits located within the field of representation, an imaginary engagement symptomatic of the uncomfortable reality of our own bodies, which we endeavour to extend, control and change through various means in a creative effort to affect greater physical, cultural or aesthetic agency.

Janine Chasseguet-Smirgel (1985) characterises the links between creativity and perversity in an analysis of the artist Hans Bellmer's sculpture/photographic work entitled "The Doll" (1936) alongside HG Well's fictional character, Dr Moreau (The Island of Dr Moreau, 1896). The latter is of interest to our examination of the Frankensteinian legacy as he might be regarded as the guiltless Frankenstein, where the relation with his creations does not shift as it does with Frankenstein. Hybridity here is not grounded in a emotional dichotomy between two monsters, but instead located in an erasure of boundaries between the human and animal. While in most mythological manimals are naturalised (as with centaurs or harpies), here it is technology that is deployed 
creatively to undo God's command that man and animals are separated. Bellmer's art work by contrast concocts a refigured female body and seems far more obviously erotic in intention: limbs are collaged into new places and in follow-on work binding the body with twine to create a new figurative landscape. The 'mastery' here is represent here through a language of bondage and sadomasochism while simultaneously the title refers obliquely to Hoffman's tale of Coppelia, The Sandman (date etc). The notion of corporeal collage is clearly referred to in the tale at multiple levels. The protagonist reports what happened when, as a child, he is discovered spying on his father and Dr Coppelius' mysterious alchemical work: "The boy can have his eyes then, and keep the use of them. But now let us observe the mechanism of the hands and feet". And with that he seized me so violently that my joints cracked, unscrewed my hands and feet, and fixed them on again this way, now that.' (91-2). The capacity of CGI to represent bodies as hybrid and with exchangeable parts is perhaps best emblemized using Bellmer's perverse corporeal imagery in the representation of the zombie nurses in the Silent Hill games (fig..). Their bodies are no longer whole, animated but no longer human, images thrown up as if from Hieronymus Bosch's images of bodies in Hell and formed as literal renditions of making the beast with two backs. The legacy of Frankenstein is then something far broader than simply a case of adaptation, but instead taps into something fundamental about the daemonic status of creativity itself and its tendency to disavow not only the real, but the guarantor of the real, death.

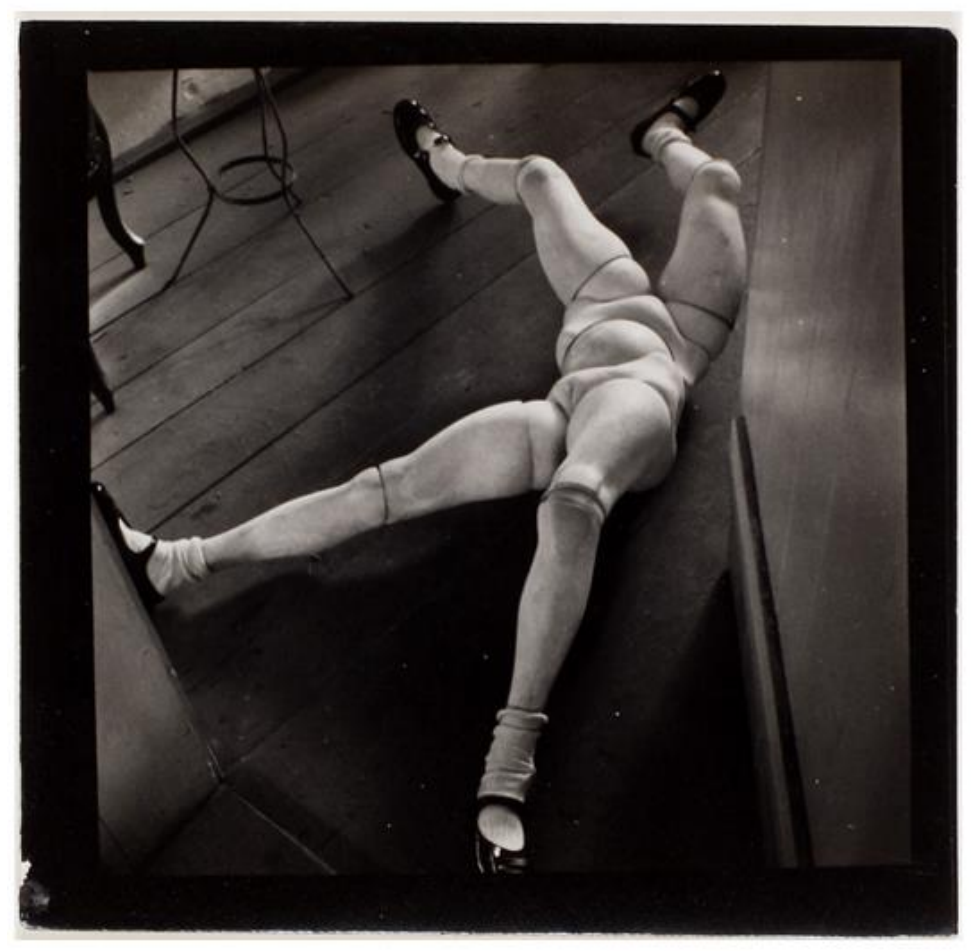




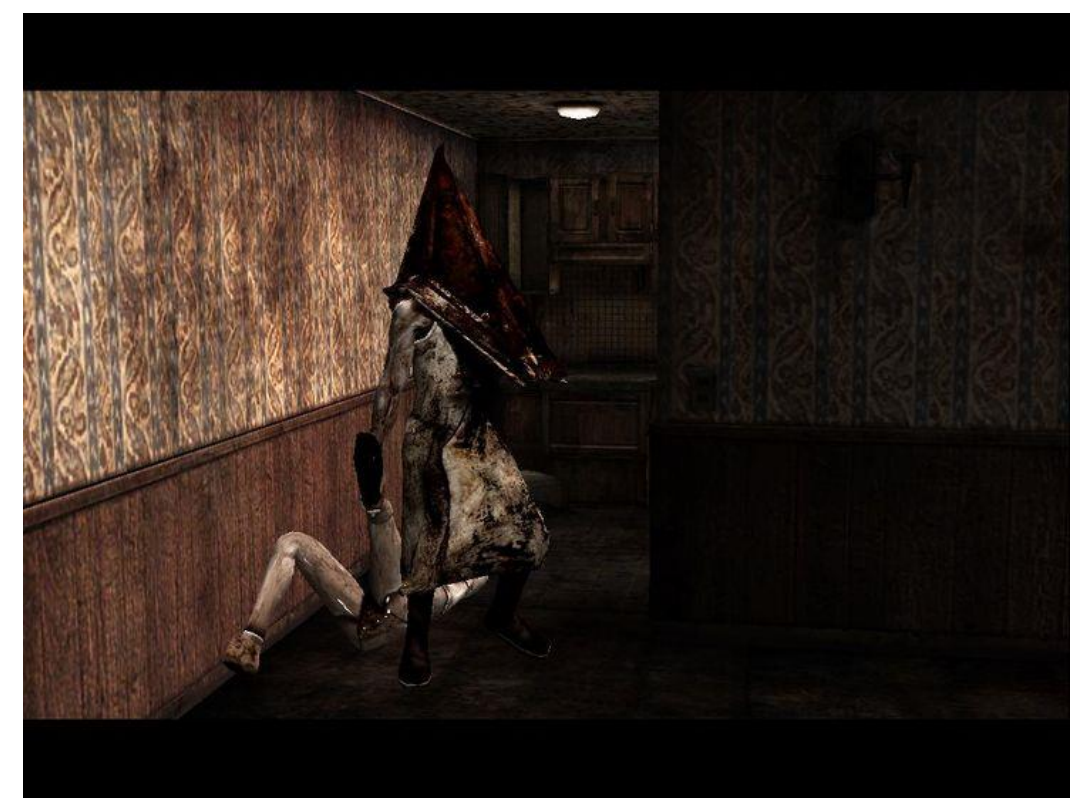

What then if the creativity we speak is not human? What if it is synthetic? Computational creativity is gaining purchase in the creative industries generally as well as in academic circles. Many games now have element designed to track player behaviours so that the game can be altered to fit the skills and habits of a player. The Horror game Left for Dead ( ), a co-operative game played over the internet is now quite old, but one of its unique selling features is 'The Director'. This is an internal procedure that has no direct representation on the screen, but instead monitors player behaviour so that if players remain static for too long a zombie horde is triggered to jolt them out of idleness. The sense of this agentic presence heightens a sense of wariness, making players feel observed and judged as if The Director is a real entity lurking behind events. There are many monsters in the game, represented in terms of the usual stuff of Horror films. However, The Director, remains unseen, without physical form, but is omnipresent, creative and perverse...at times these are features invented by increasingly paranoid players, but at others palpably the case and sent to torment players. The effect is to heighten the sense of feeling hunted, a feature reminiscent of Frankenstein, where both protagonists turn from hunter to hunted at various points in the game. This is also a feature of Frankenstein that carries forward into the zombie sub-genre, where the boundaries between life and death have broken down, and the generally tenor is of base and temporary survival rather than heroic action leading to a final resolution. The Director is not a 'boss' monster. It can't be bested, or fought, just reacted to. This presiding figure is then a monster of a different order. A child of computational creativity who is blind to human suffering or incidence. But unlike the curious Al of x's Demon Seed, he has no interest in corporeality and its effects.

Al characters are also common in games, Cortana for example in Hao becomes companion to the Cyborg hero the Master Chief (and has now been adopted by Microsoft as the identity for its adaptable and voice activated search engine). They are often rather more humanised than Lef for Dead's Director however, even a kind of romantic foil in Halo. The post-human becomes therefore more human and far less othered in these instances.

End up with Al.....the new father.

The posthuman/Al/Galvanism 
- In terms of games

- In terms of representation

- In terms of narrative structure

Death

Artificial Intelligence and computational creativity take this further to authoring may take a selfcreation using procedural generation computing modes. Collage

'Computational Creativity is a recent term used to name a form of computing that is programmed to 'learn' and from that learning to produce originality.

ii Muriel Spark $(1987,154)$ disputes the inclusion of Frankenstein into the Gothic canon of the $18^{\text {th }}$ century; however the novel is more easily regard as such when taking a longer view of the Gothic as a hybrid and modal form. Spark does however suggest that the novel 'was the first of a new and hybrid fictional species' (153). Hybridity, the 'pollution' of established categories, provides one of the watchwords of this essay. iii "Glitchers" are players who exploit errors in the game, such as gaps in between environmental assets, to gain tactical advantage (or in some cases, those who make their art from game glitches. 